\title{
Electrocardiogram of Clinically Healthy Mithun (Bos frontalis): Variation among Strains
}

\author{
Sagar Sanyal, ${ }^{1}$ Pradip Kumar Das, ${ }^{1}$ Probal Ranjan Ghosh, ${ }^{1}$ Kinsuk Das, ${ }^{1}$ Kezha V. Vupru, ${ }^{2}$ \\ Chandan Rajkhowa, ${ }^{2}$ and Mohan Mondal ${ }^{2}$ \\ ${ }^{1}$ Department of Veterinary Physiology, Faculty of Veterinary and Animal Sciences, West Bengal University of Animal and \\ Fishery Sciences, 37, Kshudiram Bose Sarani, Kolkata 700 037, India \\ ${ }^{2}$ National Research Centre on Mithun, Indian Council of Agricultural Research Jharnapani, Medziphema, Nagaland 797106, India
}

Correspondence should be addressed to Mohan Mondal,drmmondal@gmail.com

Received 15 May 2010; Accepted 23 August 2010

Academic Editor: Maria Laura Bacci

Copyright (C) 2010 Sagar Sanyal et al. This is an open access article distributed under the Creative Commons Attribution License, which permits unrestricted use, distribution, and reproduction in any medium, provided the original work is properly cited.

\begin{abstract}
A study was conducted to establish the normal electrocardiogram in four different genetic strains of mithun (Bos frontalis). Electrocardiography, cardiac electrical axis, heart rate, rectal temperature and respiration rate were recorded in a total of 32 adult male mithun of four strains $(n=8$ each). It was found that the respiration and heart rates were higher $(P<.05)$ in Manipur than other three strains. Amplitude $(P<.05)$ and duration of $\mathrm{P}$ wave and QRS complex differed $(P<.01)$ among the strains. Mizoram strain had the highest amplitude and duration of $\mathrm{P}$ wave and QRS complex. On the other hand, higher $(P<.05)$ amplitude and duration of $\mathrm{T}$ wave were recorded in Arunachalee and Mizoram strains. The mean electrical axis of QRS complex that were recorded for Arunachalee and Manipur strains were similar to that reported for other bovine species; whereas the electrical axis of QRS for Nagamese and Mizoram strains were more close to feline and caprine species, respectively. In conclusion, electrocardiogram of mithun revealed that the amplitude and duration of P wave, QRS complex and T wave were different among four different genetic strains of mithun and the electrical axis of QRS complex for Nagamese and Mizoram mithuns are dissimilar to bovine species.
\end{abstract}

\section{Introduction}

Mithun (Bos frontalis), a semi-domesticated rare ruminant of South-east Asia, is believed to have originated more than 8000 years ago and is considered to be a descendent from wild Indian gaur [1]. This prized hill animal is found mainly in four different States of the North-Eastern Hill region (NEHR) of India, namely, Arunachal Pradesh, Nagaland, Manipur, and Mizoram having different geographical locations and also in some locations of Bhutan, Myanmar, Bangladesh, and China. Mithuns from four different States of NEHR of India are reported to be genetically different from each other, and each strain of mithun is named as per the state where from they originated [2]. This massive hill animal of NEHR plays an important role in the socioeconomic and cultural life of the local population, beside it acts as a potential source of meat [1]. However, due to remoteness of their habitats and other ecological and socioeconomic factors, mithuns remain one of the least studied ungulates.
In NEHR of India, mithun meat is considered to be more tender and superior over the meat of any other species. At present, mithun farmers rear this animal at an altitude of 1000 to 3000 meters above mean sea level under free grazing condition in its natural habitat. Due to gradual denudation of forests (natural habitat of mithun) and tremendous socioeconomic and cultural importance of mithun in the life of the local tribal population, very recently initiatives are being taken to popularise economic mithun farming under semi-intensive condition with an effort to make use of mithun for benefit of human population.

The mithun normally lives in the areas where low oxygen tension prevails and thrives on very little conventional fodder. This animal is bestowed with an excellent capacity to adjust in its natural climate and to graze on stiff hill slopes with ease. In congruence with this unique characteristic, some physiological adaptations especially on the cardiovascular system are envisaged. The exploration of the exact cardiovascular physiology has profound implications 
TABLE 1: Physiological and electrocardiographic parameters (mean \pm SEM) of different strains of mithun.

\begin{tabular}{|c|c|c|c|c|}
\hline & Nagamese & Arunachalee & Mizoram & Manipur \\
\hline \multicolumn{5}{|c|}{ Physiological Parameter } \\
\hline \multirow[t]{2}{*}{ Body weight ${ }^{\dagger}(\mathrm{kg})$} & $309.3^{\mathrm{a}}$ & $284.5^{\mathrm{ab}}$ & $247.1^{\mathrm{b}}$ & $180.2^{\mathrm{c}}$ \\
\hline & \pm 88.9 & \pm 72.5 & \pm 48.3 & \pm 54.9 \\
\hline Morning Rectal & $38.1^{\mathrm{a}}$ & $36.7^{\mathrm{a}}$ & $37.6^{\mathrm{a}}$ & $39.1^{\mathrm{b}}$ \\
\hline Temperature ${ }^{\zeta}\left({ }^{\circ} \mathrm{C}\right)$ & \pm 0.4 & \pm 0.2 & \pm 0.6 & \pm 0.3 \\
\hline Evening Rectal & 38.8 & 38.7 & 38.9 & 38.8 \\
\hline Temperature $\left({ }^{\circ} \mathrm{C}\right)$ & \pm 0.05 & \pm 0.5 & \pm 0.06 & \pm 0.03 \\
\hline Respiration rate $\S$ & $29.0^{\mathrm{a}}$ & $32.5^{\mathrm{a}}$ & $30.0^{\mathrm{a}}$ & $36.6^{\mathrm{b}}$ \\
\hline (per minute) & \pm 0.5 & \pm 1.7 & \pm 0.9 & \pm 1.7 \\
\hline Heart rate ${ }^{\#}$ & $83.2^{\mathrm{ab}}$ & $78.0^{\mathrm{ac}}$ & $87.6^{\mathrm{b}}$ & $99.30^{\mathrm{d}}$ \\
\hline (per minute) & \pm 6.9 & \pm 4.09 & \pm 6.79 & \pm 12.9 \\
\hline \multicolumn{5}{|c|}{ ELECTROCARDIOGRAPHIC PARAMETER (Lead - I) } \\
\hline Amplitude of $\mathrm{P}^{¥}$ & $0.12^{\mathrm{a}}$ & $0.12^{\mathrm{a}}$ & $0.13^{\mathrm{b}}$ & $0.10^{\mathrm{c}}$ \\
\hline$(\mathrm{mV})$ & \pm 0.01 & \pm 0.02 & \pm 0.01 & \pm 0.00 \\
\hline Duration of $\mathrm{P}^{€}$ & $0.06^{\mathrm{a}}$ & $0.05^{\mathrm{a}}$ & $0.06^{\mathrm{b}}$ & $0.04^{\mathrm{c}}$ \\
\hline (s) & \pm 0.001 & \pm 0.001 & \pm 0.002 & \pm 0.002 \\
\hline Amplitude of & $0.37^{\mathrm{a}}$ & $0.36^{\mathrm{a}}$ & $0.50^{\mathrm{b}}$ & $0.28^{\mathrm{c}}$ \\
\hline $\mathrm{QRS}^{\infty}(\mathrm{mV})$ & \pm 0.07 & \pm 0.03 & \pm 0.08 & \pm 0.08 \\
\hline Duration of & $0.045^{\mathrm{a}}$ & $0.044^{\mathrm{a}}$ & $0.055^{\mathrm{b}}$ & $0.042^{\mathrm{a}}$ \\
\hline $\mathrm{QRS}^{\partial}(\mathrm{s})$ & \pm 0.001 & \pm 0.002 & \pm 0.001 & \pm 0.001 \\
\hline Amplitude of $\mathrm{T}^{\Uparrow}$ & $0.21^{\mathrm{a}}$ & $0.25^{\mathrm{b}}$ & $0.30^{c}$ & $0.20^{\mathrm{a}}$ \\
\hline$(\mathrm{mV})$ & \pm 0.024 & \pm 0.025 & \pm 0.033 & \pm 0.024 \\
\hline Duration of $\mathrm{T}^{\theta}$ & $0.06^{\mathrm{a}}$ & $0.08^{\mathrm{b}}$ & $0.09^{\mathrm{b}}$ & $0.06^{\mathrm{a}}$ \\
\hline (s) & \pm 0.001 & \pm 0.003 & \pm 0.002 & \pm 0.001 \\
\hline Mean Electrical & $+114^{\circ}$ & $-12^{\circ}$ & $+34^{\circ}$ & $-12^{\circ}$ \\
\hline axis in (frontal plane) & $\left(+70^{\circ}\right.$ to $\left.+167^{\circ}\right)$ & $\left(-90^{\circ}\right.$ to $\left.+60^{\circ}\right)$ & $\left(-128^{\circ}\right.$ to $\left.+170^{\circ}\right)$ & $\left(-90^{\circ}\right.$ to $\left.+60^{\circ}\right)$ \\
\hline
\end{tabular}

$P$ value is as follows, respectively

${ }^{\dagger} P<.01,{ }^{\zeta} P<.01,{ }^{\S} P<.05,{ }^{\#} P<.05,{ }^{¥} P<.05, €_{P<.01,}{ }^{\infty} P<.05,{ }^{\partial} P<.05,{ }^{\natural} P<.05,{ }^{\theta} P<.05$

$\mathrm{a}, \mathrm{b}, \mathrm{c}, \mathrm{d}$ Mean bearing different superscript in the same row differ significantly.

on mapping of fatigue score and draught power as well as various fields of health and production management system.

Electrocardiography is an inexpensive, noninvasive technique that entails useful information in classification of arrhythmias, diagnosing conduction abnormalities and also acts as a valuable aid in prognostic and therapeutic considerations [3-5]. The potential use of electrocardiogram (ECG) is well recognized in cattle $[6,7]$ and horse [8]. Electrical axis (EA) determined on QRS is a vector originating at the centre of Einthoven's triangle representing the direction of the ventricular activation process as projected in the plane of limb leads. EA provides important clues for derivation of ECGpathological correlation and the degree of deviation refers to either ventricular activities or intermittent conduction disturbances [9]. Mean electrical axis traditionally applied to ventricular depolarization represents the average direction of electrical potential generated during cardiac cycle and is useful for suggesting chamber enlargement or intraventricular conduction defects $[10,11]$. Like other ruminants, studies on ECG pattern vis-à-vis cardiac electrical axis of different strains of mithun would be helpful for diagnosis of ventricu- lar conduction defects, ventricular hypertrophy, pulmonary embolism, obstructive lung diseases, and other associated haemodynamic abnormalities. As there is no information available on ECG in this species, the present study is hoped to serve as a scaffold in the field of electrophysiology of Mithun. Hence, the purpose of this study was to establish normal electrocardiogram in four different genetic strains of mithun using the standard bipolar limb leads (I, II, and III) and augmented unipolar limb leads (aVL, aVR, and aVF).

\section{Materials And Methods}

2.1. Study Area and Climate. The study was conducted at Medziphema Farm of the National Research Centre on Mithun, Indian Council of Agricultural Research, Nagaland located between $93.5^{\circ} \mathrm{E}$ and $25.5^{\circ} \mathrm{N}$. The experiment was completed within 30 days. The mean $( \pm$ SEM) atmospheric temperature, relative humidity, rain fall, and wind velocity during the experimental period was recorded to be $26.3 \pm$ $3.1^{\circ} \mathrm{C}, 63.5 \pm 0.9 \%, 3.2 \pm 1.4 \mathrm{~mm}$, and $24.2 \pm 10.6 \mathrm{~km} / \mathrm{hour}$, respectively. 


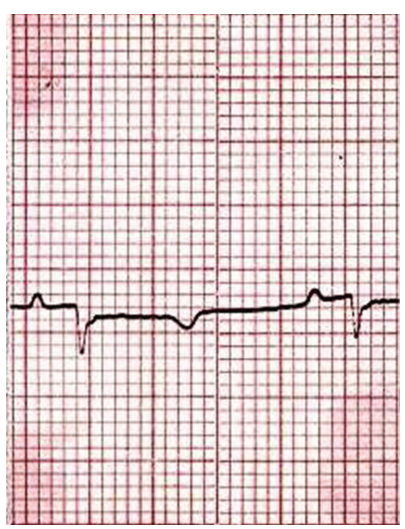

I

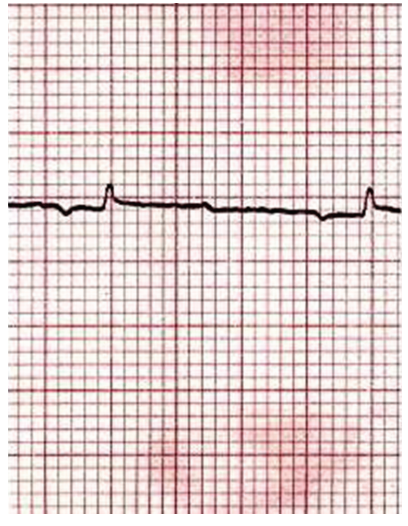

aVR

(a)

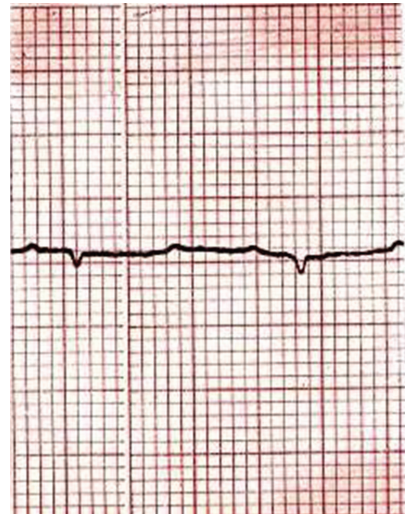

II

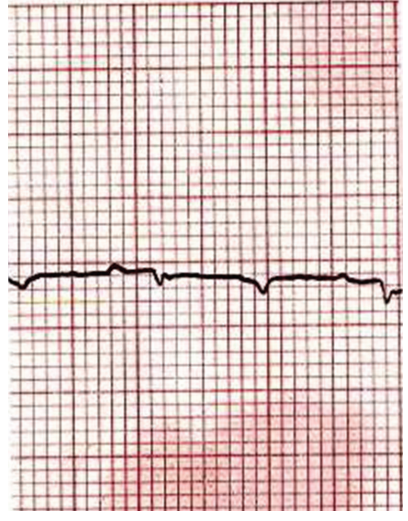

$\mathrm{aVL}$

(b)

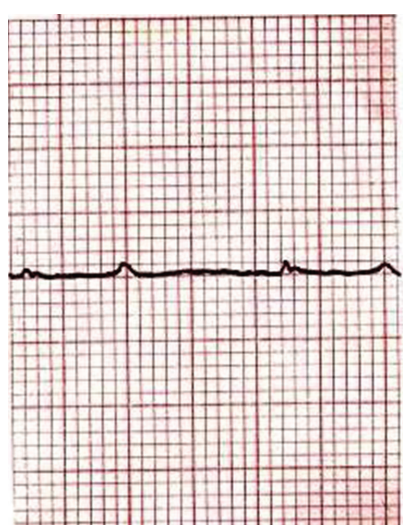

III

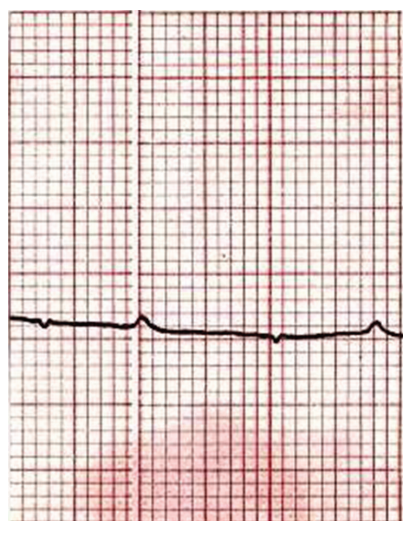

$\mathrm{aVF}$

(c)

FIgURE 1: Electrocardiogram of Nagamese mithun (Bos frontalis).

2.2. Experimental Animals. A total of 32 healthy male mithuns from four different strains, namely, Nagamese, Arunachalee, Mizoram, and Manipur ( $n=8$ for each strain) with age and body weight ranged between 40 and 70 months, and 126 and $380 \mathrm{~kg}$ were selected for the present study after proper clinical examination and based on farm records.

2.3. Experimental Parameters. The electrocardiogram (ECG) along with rectal temperature and respiration rate were measured in all animals. The rectal temperature was recorded twice a day at 0600 and $1700 \mathrm{~h}$ using electronic digital thermometer (OMRON, Japan). The respiration rate was also recorded. ECG was recorded by six-channel CARDIART-108 T/MK-VI (BPL, India) portable ECG machine as per standard procedure [12]. ECG tracings were recorded on standing posture. The machine was calibrated at $1 \mathrm{mV}=10 \mathrm{~mm}$ and paper speed of $25 \mathrm{~mm} / \mathrm{s}$. The right and left armed electrode were attached proximal to olecranon process on the caudal aspects of the appropriate four legs, whereas hind leg electrodes were attached over stifle joint on the anterior aspects of appropriate hind legs. The cardiac electrical axis of QRS of different strains of Mithun was determined from ECG using hexaxial reference system [10,
11]. Heart rate was calculated from ECG tracing by R-R method [13]. Amplitude and duration of $\mathrm{P}$ wave, QRS complex, and $\mathrm{T}$ wave were traced in all three standards bipolar and three unipolar leads.

2.4. Statistical Analyses. Mean values and their standard errors of the mean (SEM) for each parameter were calculated using GraphPad Prism 4.01 software (GraphPad Software, Inc., San Diego, CA). An analysis of variance with Bonferroni posttest was carried out to examine the differences among strains for each parameter using the same software. Values of $P<.05$ were considered significant.

\section{Results}

3.1. Rectal Temperature, Respiration, and Heart Rates. The mean $( \pm$ SEM) body weight, morning and evening rectal temperature, respiration, and heart rates recorded for Nagamese, Arunachalee, Mizoram, and Manipur strains are presented in Table 1. The mean body weight differed significantly $(P<.01)$ among strains of Mithun (Table 1$)$. Morning rectal temperature of Manipur strain was the highest and differed significantly $(P<.01)$ from all other 


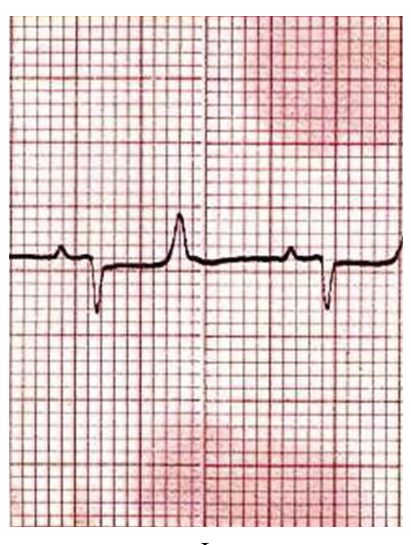

I

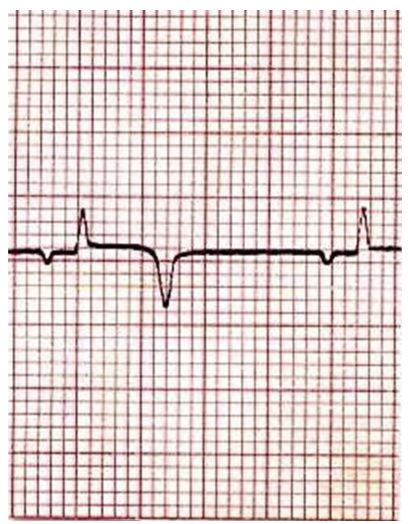

$\mathrm{aVR}$

(a)

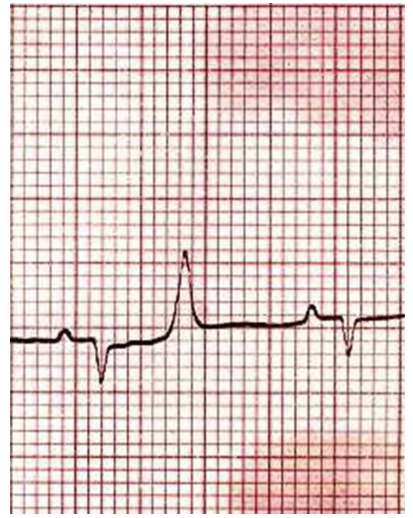

II

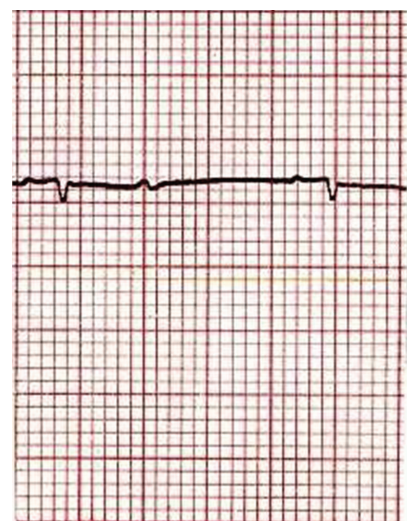

$\mathrm{aVL}$

(b)

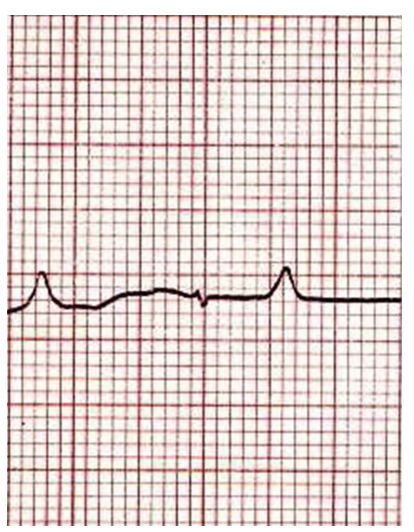

III

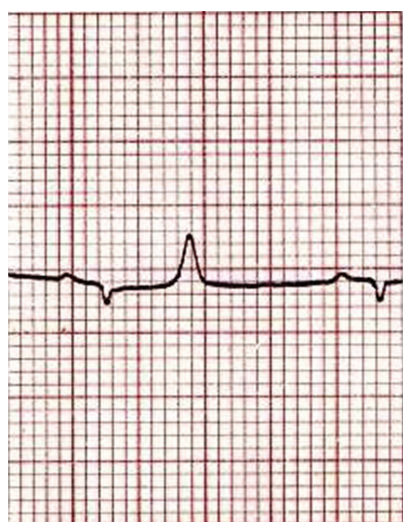

$\mathrm{aVF}$

(c)

Figure 2: Electrocardiogram of Arunachalee mithun (Bos frontalis).

three strains. No significant differences $(P>.05)$ were observed for evening rectal temperature among the strains. Manipur strain exhibited significantly $(P<.01)$ higher respiration rate $(36.6 \pm 1.7 / \mathrm{min})$ than other strains. The heart rate of Manipur strain $(99.3 \pm 12.9 / \mathrm{min})$ was recorded to be the highest, and it differed significantly $(P<.01)$ with other three strains whereas the heart rate of Mizoram strain $(87.6 \pm 6.7 / \mathrm{min})$ differed significantly with Nagamese and Arunachalee strains.

3.2. Electrocardiogram. Electrocardiograms (ECG) of different strains of mithun are presented in Figures 1-4. The amplitude and duration of $\mathrm{P}$ wave, QRS complex, $\mathrm{T}$ wave of lead-I, and mean electrical axis with axis deviation in frontal plane as derived from ECG tracing are presented in Table 1. Both the amplitude and duration of $\mathrm{P}$ wave were found to differ significantly $(P<.05)$ among the strains. The highest amplitudes and duration of $\mathrm{P}$ wave were observed in Mizoram strain $(0.129 \pm 0.014 \mathrm{mV}$ and $0.048 \pm 0.001 \mathrm{~s}$, resp.) followed by Nagamese $(0.121 \pm 0.014 \mathrm{mV}$ and 0.055 $\pm 0.001 \mathrm{~s}$, resp.), Arunachalee $(0.120 \pm 0.015 \mathrm{mV}$ and 0.048 $\pm 0.001 \mathrm{~s}$, resp. $)$ and Manipur $(0.100 \pm 0.001 \mathrm{mV}$ and 0.039 $\pm 0.002 \mathrm{~s}$, resp.) strains. The highest amplitude $(0.494 \pm$
$0.075 \mathrm{mV})$ and duration $(0.055 \pm 0.001 \mathrm{~s})$ of QRS complex were recorded in Mizoram strain and it was significantly different $(P<.05)$ from other three strains. Higher $(P<$ $.05)$ amplitude and duration of $\mathrm{T}$ wave were recorded in Arunachalee $(0.250 \pm 0.025 \mathrm{mV}$ and $0.082 \pm 0.003 \mathrm{~s}$, resp. $)$ and in Mizoram $(0.300 \pm 0.033 \mathrm{mV}$ and $0.085 \pm 0.002 \mathrm{~s}$, resp.) strains.

The electrical axis deviations with mean electrical axis of QRS complex in frontal plane are presented in Figures 5 and 6. The cardiac electrical axis for Nagamese, Arunachalee, Mizoram, and Manipur strains were calculated to be $+70^{\circ}$ to $+167^{\circ}\left(+114^{\circ}\right),-90^{\circ}$ to $+60^{\circ}\left(-12^{\circ}\right),-128^{\circ}$ to $+170^{\circ}\left(+34^{\circ}\right)$ and $-90^{\circ}$ to $+60^{\circ}\left(-12^{\circ}\right)$, respectively.

\section{Discussion}

To the best of our knowledge, this is the first report ever that describes the electrocardiogram in clinically healthy mithuns, particularly strain-specific differences in electrocardiograms among different strains. Electrocardiography, a noninvasive technique, is generally a method of choice for evaluating electrical activity of heart and determining irregularities of cardiac rhythm $[13,14]$. In small animals 

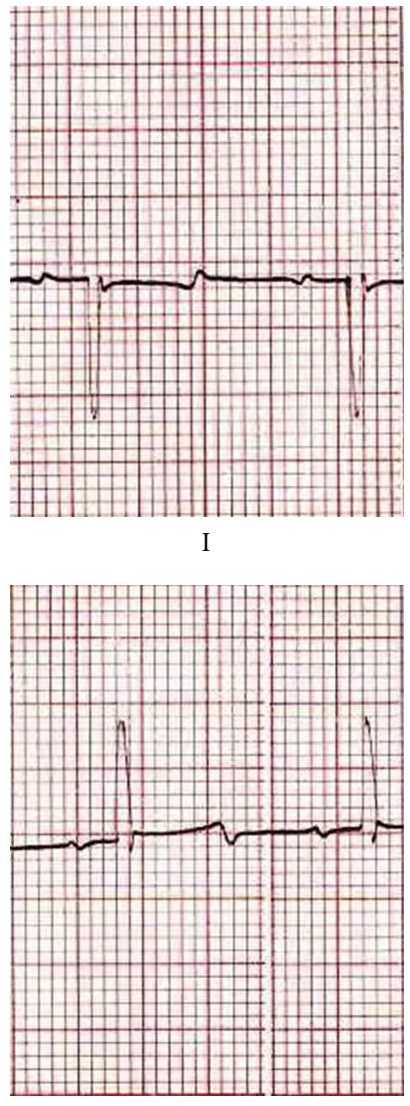

$\mathrm{aVR}$

(a)

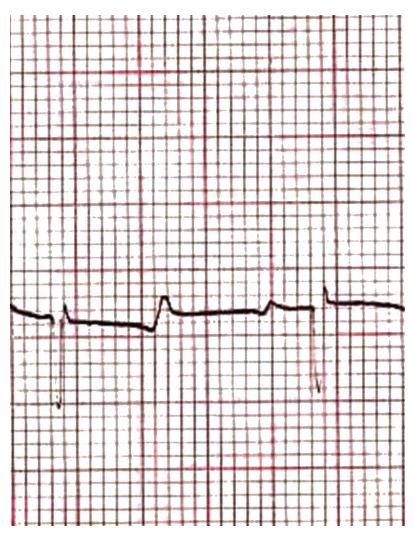

II

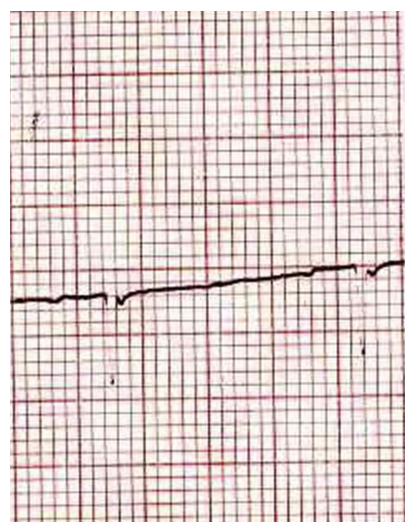

$\mathrm{aVL}$

(b)

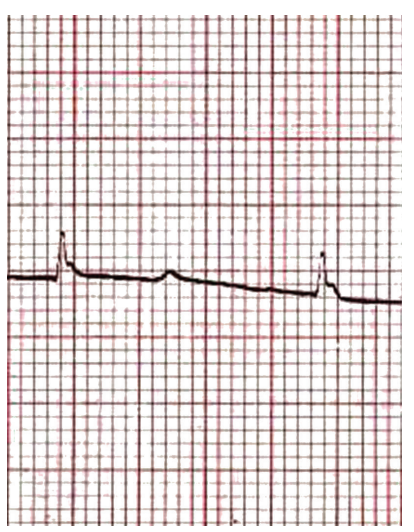

III

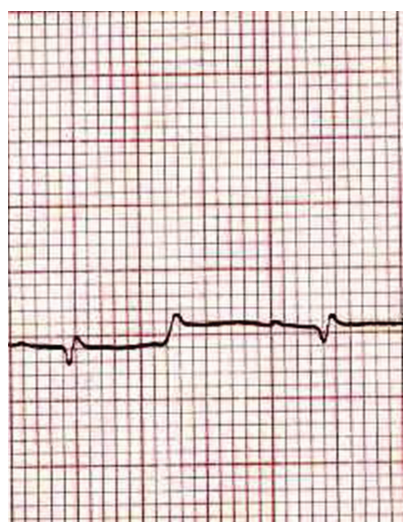

$\mathrm{aVF}$

(c)

Figure 3: Electrocardiogram of Mizoram mithun (Bos frontalis).

and human beings, it can be used for detecting cardiac hypertrophy and dilation $[15,16]$. However, in large animals, because of deep penetration of Purkinje fibres in the myocardium, the ECG is not very helpful for detecting cardiac chambers' enlargement [17]. Therefore, in cattle and similarly in mithun, the ECG may mostly be used for detection of cardiac arrhythmias. In order to use a trace for this purpose, it should have clear electrocardiographic waves and complexes. The bipolar limb leads and augmented unipolar limb leads used in the present investigation for mithun were prudent to present electrocardiographic parameters as standard values.

The purpose of the present study was to assess the electrophysiological activity of heart of mithun, and to compare it among the various strains. As social behavior, particularly the temperamental behavior of four different strains of mithun is different since its domestication; hence along with ECG, some extraphysiological parameters, namely, rectal temperature, respiration rate, and heart rate were also studied to assess the cardiovascular physiology of mithun as a whole.

Though the origin of four different strains of mithuns used in the present study was from four respective states of India, they were reared from birth at the farms of the
National Research Centre on Mithun in Nagaland State. Hence, the difference in rectal temperature as recorded in different strains of mithun in the present study was probably due to strain variation. The variation in respiration rate among different strains may be due to significant differences in body weight (Table 1). Similarly, higher heart rate in Manipur strain may be due to lower body weight.

The careful and detailed study of different waves of the ECG tracing of mithun in the present investigation showed some unique features which can be compared with other domesticated animals. The variability of the QRS complex in different strains of mithun produces different positions of mean frontal plane of vectors. The narrowest angle $\left(+70^{\circ}\right.$ to $+167^{\circ}$ ) of ventricular activation has been found in Nagamese strain with a mean of $+114^{\circ}$. This may be due to size of the heart in comparison to their body size. This cardiac axis is similar to feline species [16] considering the positivity of angle of activation. The widest ventricular activation field $\left(-128^{\circ}\right.$ to $\left.+170^{\circ}\right)$ with a mean electrical axis of $+34^{\circ}$ as found in Mizoram strain is essentially similar to caprine species [17-19]. This widest ventricular activation process in these caprine and mithun may be due to peculiarity of distribution of conducting fibers. In most mammals, the 


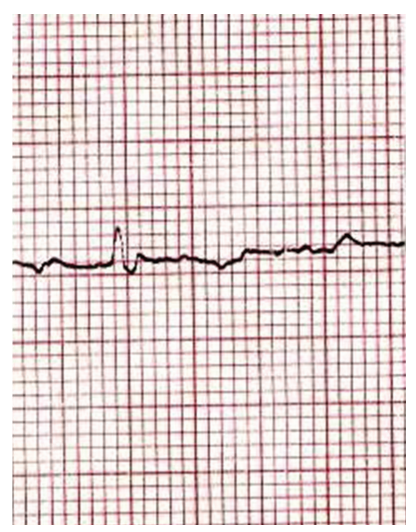

I

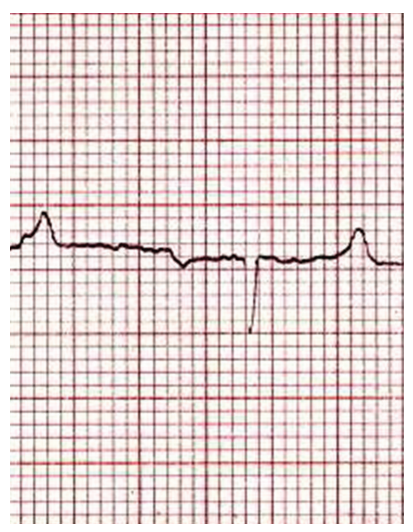

$\mathrm{aVR}$

(a)

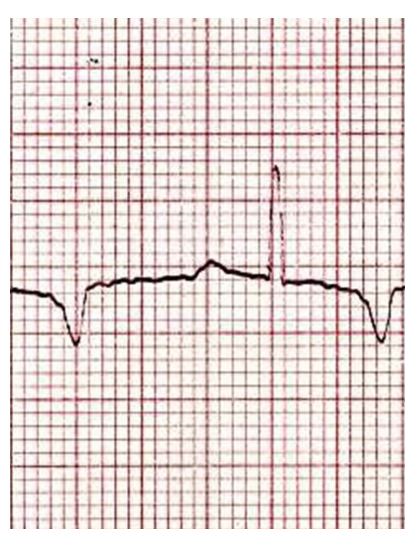

II

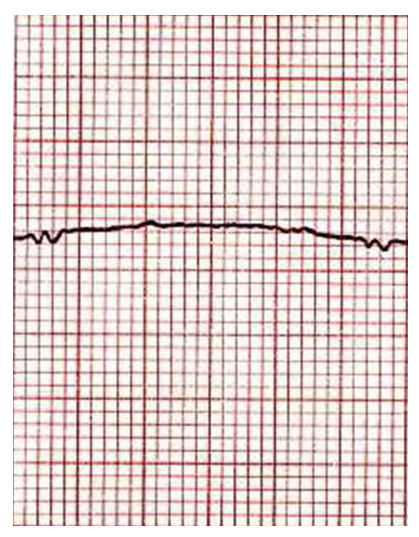

$\mathrm{aVL}$

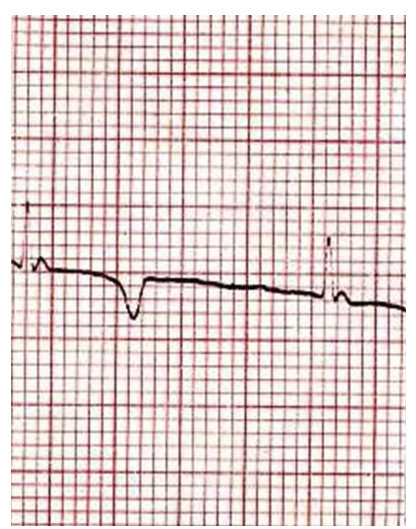

III

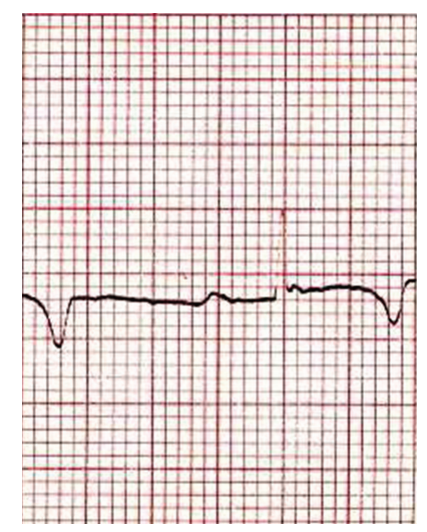

$\mathrm{aVF}$

(c)

FIGURE 4: Electrocardiogram of Manipur mithun (Bos frontalis).

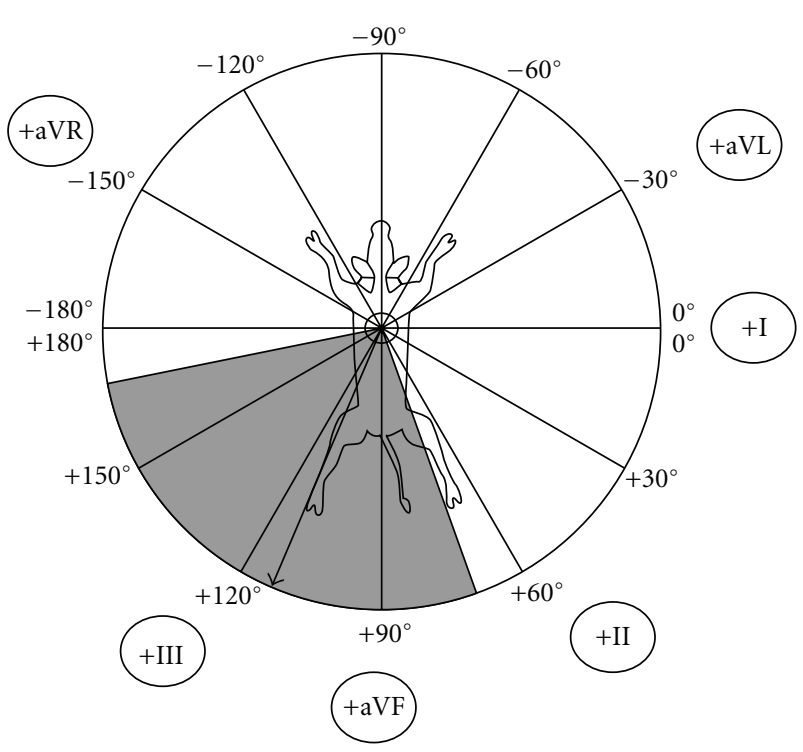

Nagamese strain

(a)

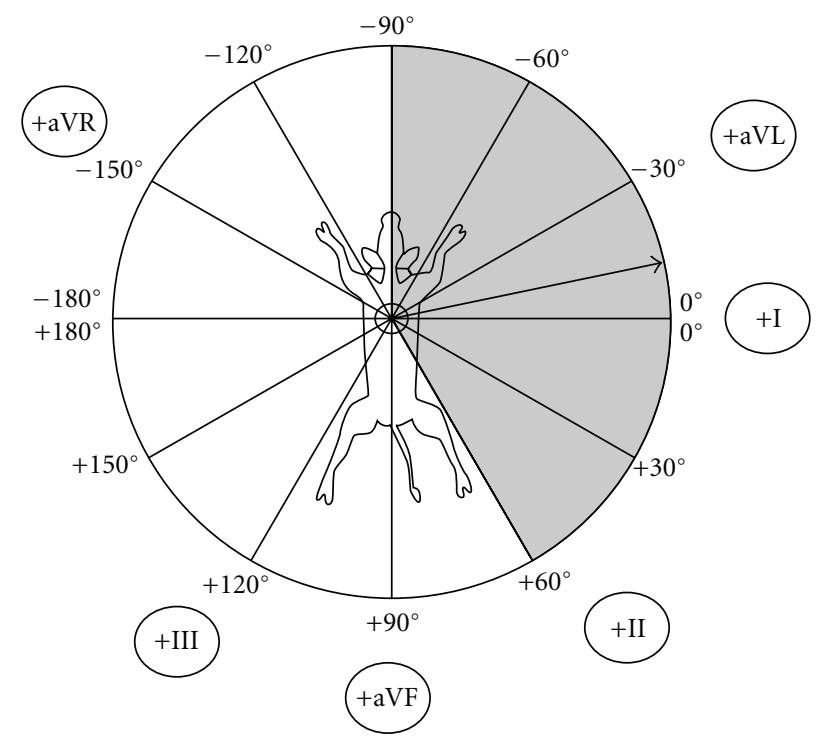

Arunachalee strain

(b)

FIgURE 5: Cardiac electrical axis of Nagamese and Arunachalee Strain of Mithun (Bos frontalis). 


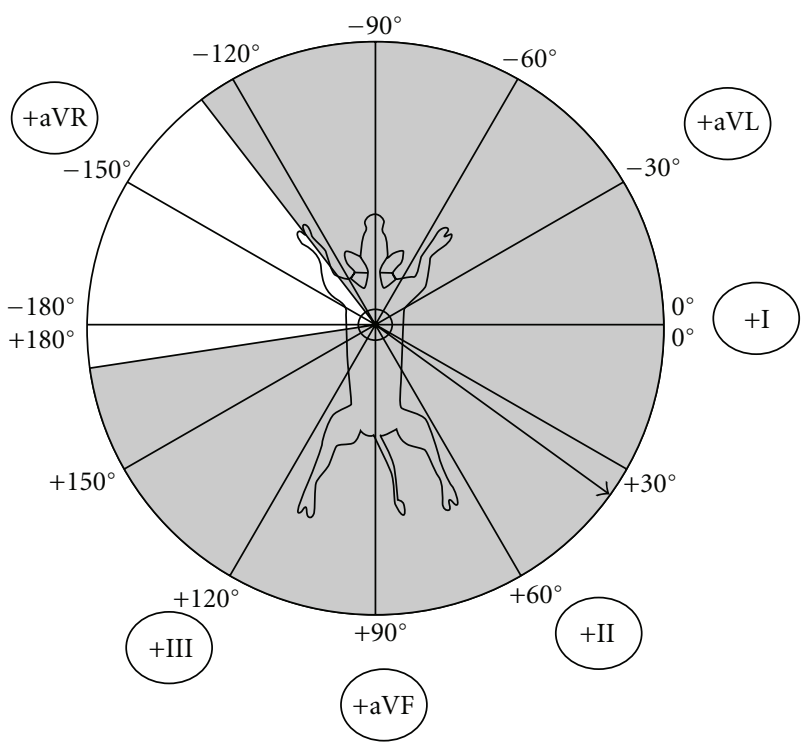

Mizorum strain

(a)

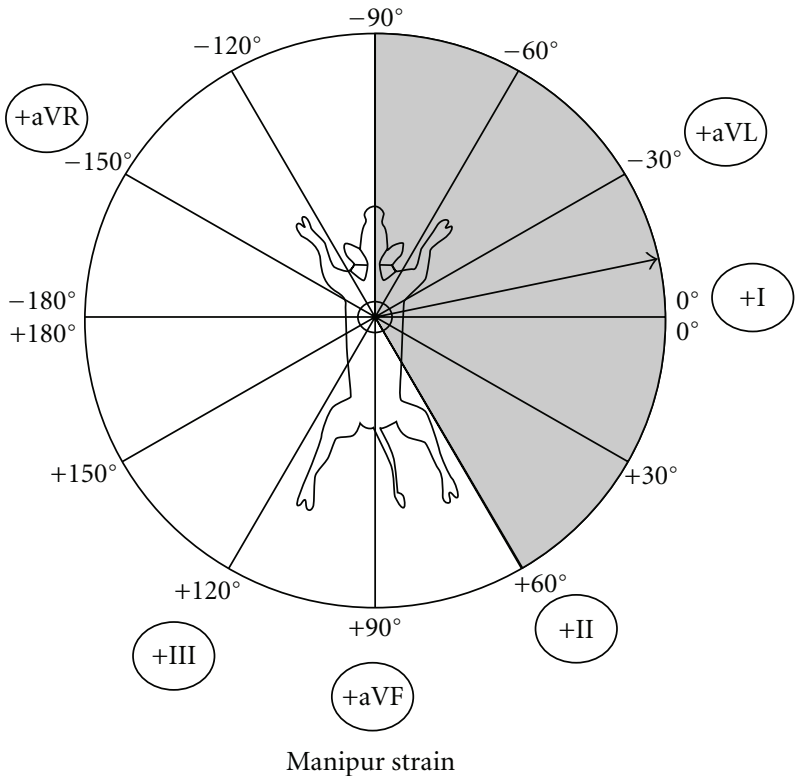

(b)

Figure 6: Cardiac electrical axis of Mizoram and Manipur strain of Mithun (Bos frontalis).

mean electrical activity or vector during inscription of QRS complex is directed towards the apex of the heart [20]. Moreover, due to high penetration of Purkinje fiber up to epicardium with a higher conduction rate, the ventricular wall excited rapidly with a burst associated with almost simultaneous excitation of all areas of the left ventricle except a small apical epicardial area [21]. The finding of this study indicates a considerable variability of the QRS complex in normal ECG [21]. The identical pattern of electrical axis of Arunachalee and Manipur strains was between $-90^{\circ}$ to $+60^{\circ}$ with a mean of $-12^{\circ}$, and it was moderately wide and almost similar to that reported for bovine [22]. Although, there are great variations in QRS complex in ruminants including mithuns, some possible explanation for these differences may be due to variation in depolarization pathways, differences in position of the heart within the thorax, or differences within the shape or conductivity of the torso.

In conclusion, electrocardiogram of mithun revealed that the amplitude and duration of $\mathrm{P}$ wave, QRS complex, and $\mathrm{T}$ wave were different among four different genetic strains of mithun and the electrical axis of QRS complex for Nagamese and Mizoram mithuns are dissimilar to bovine species.

\section{Acknowledgment}

The authors are thankful to the Director of National Research Centre on Mithun, Indian Council of Agricultural Research, Jharnapani, Nagaland, India for permitting the authors for conducting the present study at NRC on Mithun farms.

\section{References}

[1] F. J. Simoons, "Gayal or mithun," in Evolution of Domesticated Animals, I. L. Manson, Ed., pp. 34-36, Longman, London, UK, 1984.

[2] S. Bhusan, D. Sharma, C. Rajkhowa, and K. M. Bujarbaruah, "RAPD profile for four mithun populations," Indian Journal of Animal Sciences, vol. 77, no. 7, pp. 630-632, 2007.

[3] G. F. Fregin, "Electrocardiography," Veterinary Clinics of North America, vol. 1, no. 2, pp. 419-432, 1985.

[4] M. S. Claxton, "Electrocardiographic evaluation of arrhythmias in six cattle," Journal of the American Veterinary Medical Association, vol. 192, no. 4, pp. 516-521, 1988.

[5] A. Rezakhani and A. A. Paphan, "Study on the prevalence of cardiac arrhythmias in dairy calves," Iranian Journal of Veterinary Research, vol. 3, pp. 257-162, 2002.

[6] L. DeRoth, "Electrocardiographic parameters in the normal lactating Holstein cow," Canadian Veterinary Journal, vol. 21, no. 10, pp. 271-277, 1980.

[7] N. Machida, Y. Okamata, S. Minami, Y. Yamaga, and K. Kagota, "Cardiac arrhythmias in normal Holstein heifers," Journal of the Japan Veterinary Medical Association, vol. 44, pp. 1176-1386, 1991.

[8] I. Ayala, A. Montes, J. L. Benedito et al., "Modifications of the form and amplitude of the electrocardiographic QRS complex during growth in the Spanish-bred horse," Journal of Veterinary Medicine A, vol. 45, no. 5, pp. 309-317, 1998.

[9] A. Castellanos and L. Lemberg, "A programme introduction to the electrical axis and action potential," Tempa Tracings, vol. 34, p. 114, 1974.

[10] M. J. Swenson and W. O. Reece, Dukes Physiology of Domestic Animals, Panima, New Delhi, India, 11th edition, 1996.

[11] J. A. Ahmed, S. Sanyal, P. K. Das, and S. K. Thakur, "Electrocardiographic studies in horse," Indian Journal of Animal Health, vol. 43, pp. 122-126, 2004. 
[12] C. Rosendorff, Essential Cardiology. Principleas and Practice, W. B. Saunders, Philadelphia, Pa, USA, 2001.

[13] A. Rezakhani, A. A. Paphan, and S. Shekarfroush, "Analysis of base apex lead electrocardiograms of normal dairy cows," Veterinarski Arhiv, vol. 74, no. 5, pp. 351-358, 2004.

[14] A. Rezakhani, A. A. Paphan, and H. R. Gheisari, "Cardiac dysrhythmias in clinically healthy heifers and cows," Revue de Medecine Veterinaire, vol. 155, no. 3, pp. 159-162, 2004.

[15] D. Novosel, G. Noll, and T. F. Lüscher, "Corrected formula for the calculation of the electrical heart axis," Croatian Medical Journal, vol. 40, no. 1, pp. 77-79, 1999.

[16] L. P. Tilley, Essential of Canine and Feline Electrocardiography, Lea \& Fabiger, Philadelphia, Pa, USA, 3rd edition, 1992.

[17] I. H. Choi, S. K. Kim, C. C. Kim, I. B. Choi, and N. S. Kim, "Studies on electrocardiogram of the healthy Korean native goat.I. Standard and unipolar limb leads," Korean Journal of Veterinary Clinical Medicine, vol. 14, pp. 319-337, 1997.

[18] N. H. Mohan, D. Niyogi, and H. N. Singh, "Analysis of normal electrocardiograms of Jamunapari goats," Journal of Veterinary Science, vol. 6, no. 4, pp. 295-298, 2005.

[19] R. L. Hamlin and A. M. Scher, "Ventricular activation process and genesis of QRS complex in the goat," American Journal of Physiology, vol. 200, pp. 223-228, 1961.

[20] R. L. Hamlin and C. R. Smith, "Categorization of common domestic mammals based upon their ventricular activation process," Annals of the New York Academy of Sciences, vol. 127, no. 1, pp. 195-203, 1965.

[21] M. Szabuniewicz and D. R. Clark, "Analysis of the electrocardiograms of 100 normal goats," American Journal of Veterinary Research, vol. 28, no. 123, pp. 511-516, 1967.

[22] H. Amory, F. A. Rollin, B. C. Genicot, J. M. Beduin, and P. M. Lekeux, "Comparative study of the body surface electrocardiogram in double-muscled and conventional calves," Canadian Journal of Veterinary Research, vol. 57, no. 3, pp. 139-145, 1993. 

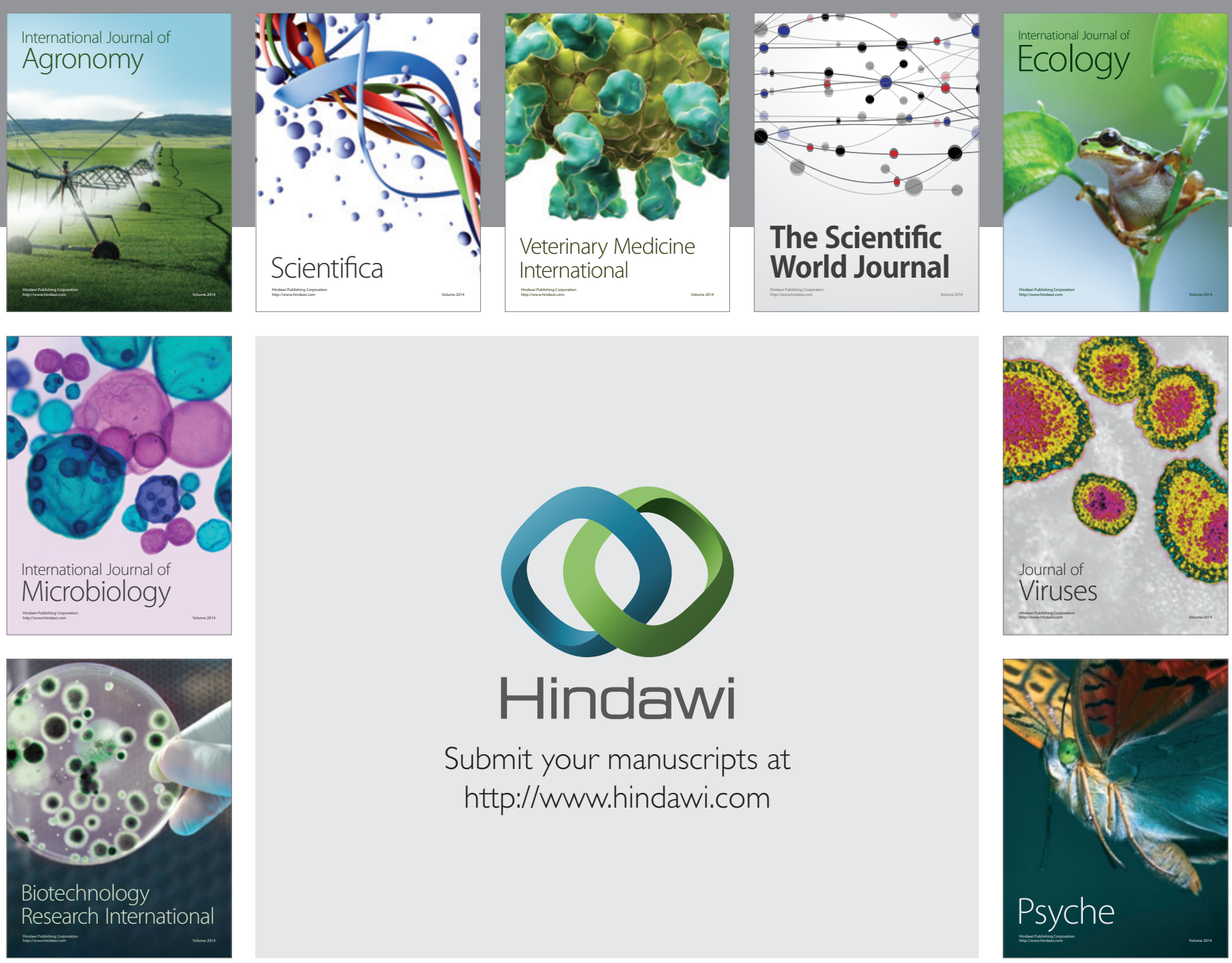

Submit your manuscripts at

http://www.hindawi.com
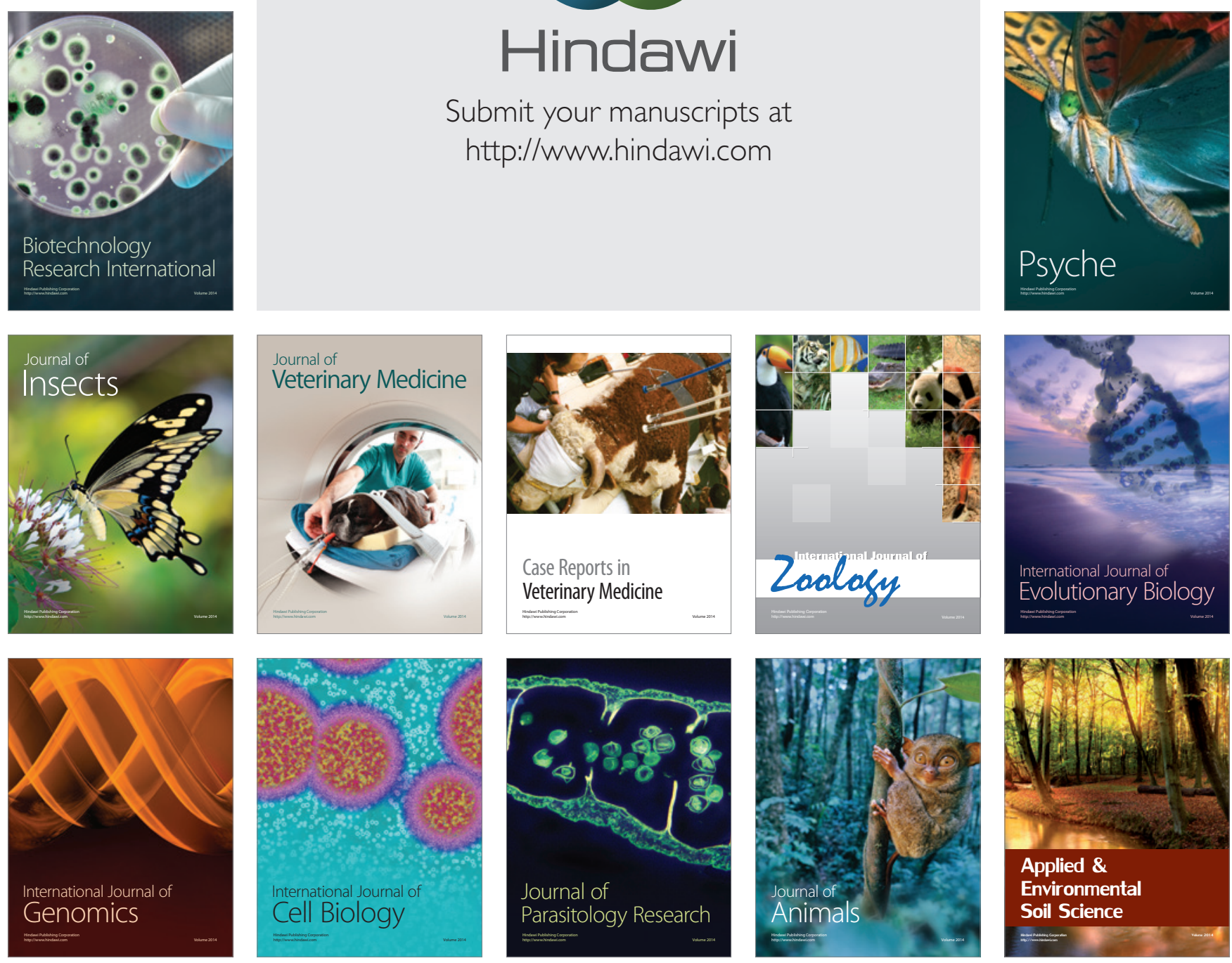